University of Nebraska - Lincoln

DigitalCommons@University of Nebraska - Lincoln

Faculty Publications: Department of

Entomology

Entomology, Department of

2002

Geostatistical Analysis of the Small-Scale Distribution of

European Corn Borer (Lepidoptera: Crambidae) Larvae and

Damage in Whorl Stage Corn

\author{
Robert J. Wright \\ University of Nebraska-Lincoln, rwright2@unl.edu \\ Terry A. Devries \\ University of Nebraska, tdevries1@unl.edu \\ Linda J. Young \\ University of Nebraska, lyoung3@unl.edu \\ Keith J. Jarvi \\ University of Nebraska, kjarvi1@unl.edu \\ Ronald C. Seymour \\ University of Nebraska, rseymour1@unl.edu
}

Follow this and additional works at: https://digitalcommons.unl.edu/entomologyfacpub

Part of the Entomology Commons

Wright, Robert J.; Devries, Terry A.; Young, Linda J.; Jarvi, Keith J.; and Seymour, Ronald C., "Geostatistical Analysis of the Small-Scale Distribution of European Corn Borer (Lepidoptera: Crambidae) Larvae and Damage in Whorl Stage Corn" (2002). Faculty Publications: Department of Entomology. 192.

https://digitalcommons.unl.edu/entomologyfacpub/192

This Article is brought to you for free and open access by the Entomology, Department of at DigitalCommons@University of Nebraska - Lincoln. It has been accepted for inclusion in Faculty Publications: Department of Entomology by an authorized administrator of DigitalCommons@University of Nebraska - Lincoln. 


\title{
Geostatistical Analysis of the Small-Scale Distribution of European Corn Borer (Lepidoptera: Crambidae) Larvae and Damage in Whorl Stage Corn
}

\author{
R. J. WRIGHT,,${ }^{1,2}$ T. A. DEVRIES, ${ }^{2}$ L. J. YOUNG,${ }^{3}$ K. J. JARVI, ${ }^{4}$ and R.C. SEYMOUR ${ }^{5}$ \\ Department of Entomology, University of Nebraska-Lincoln, Lincoln, NE 68583
}

\begin{abstract}
Environ. Entomol. 31(1): 160-167 (2002)
ABSTRACT The small-scale spatial distribution of European corn borer, Ostrinia nubilalis (Hübner), larvae and damage in whorl stage corn, Zea mays L., was characterized using geostatistics. Spatial distribution of O. nubilalis larval feeding damage was studied at Clay Center, North Platte, and Concord, NE, during June-July 1992-1994, and spatial distribution of O. nubilalis larvae and damage was studied at Clay Center in June 1997. Semivariograms were calculated to model the change in spatial correlation with increasing distance between samples. Spatial distribution of larval damage during 1992-1994 was best described using a spherical model. Damage was spatially correlated among plants at distances up to $2.84 \mathrm{~m}$ apart. The spatial distribution of larvae in 1997 was best described using an exponential model for three of seven data sets, a spherical model for one of seven data sets and no model fit three of seven data sets. Larvae were spatially correlated among plants at distances up to $3.05 \mathrm{~m}$ apart. These data have implications for developing sampling plans for management of $O$. nubilialis, and for site-specific agriculture.
\end{abstract}

KEY WORDS maize, geostatistics, European corn borer

THE EUROPEAN CORN borer, Ostrinia nubilalis (Hübner) is an important pest of Zea mays $\mathrm{L}$. (field corn, sweet corn, and seed corn) production systems in the United States (Mason et al. 1996). In much of the central U.S. Corn Belt, there are two generations annually. Because of differences in the biology of $O$. nubilalis on whorl and reproductive stage corn, sampling procedures and economic injury levels vary for the two generations (Calvin and Van Duyn 1999). In whorl stage corn, management decisions are based on the frequency of damaged plants and the number of live larvae per damaged plant. In reproductive stage corn management decisions are based on egg mass densities alone. Although recommended sampling procedures for O. nubilalis in whorl and reproductive stage corn have been described (Mason et al. 1996, Tollefson and Calvin 1994), there is little research on the distribution of European corn borer on whorl stage corn.

Previous research on European corn borer distribution in corn has primarily focused on reproductive stage corn. Calvin et al. (1986) determined that $O$.

\footnotetext{
${ }^{1}$ E-mail: rwright2@unl.edu.

${ }^{2}$ South Central Research \& Extension Center, Clay Center NE 68933-0066.

${ }^{3}$ Department of Biometry, University of Nebraska-Lincoln, Lincoln, NE 68583.

${ }^{4}$ Northeast Research \& Extension Center, Norfolk, NE 68701.

${ }^{5}$ West Central Research \& Extension Center, North Platte, NE 69101. Currrent address: Adams County Cooperative Extension, P. O. Box 30, University of Nebraska, Hastings, NE 68901.
}

nubilalis egg masses were randomly dispersed in reproductive stage field corn, based on the mean-variance relationship. Shelton et al. (1986) report similar conclusions from studies on sweet corn in late whorl to reproductive stages. Parameters of the mean-variance model indicate that larvae are highly aggregated, but become less so as the larvae mature. Sorensen et al. (1995) developed a sequential sampling plan for egg masses on reproductive stage field corn, based on the mean-variance relationship.

Earlier work by work by Chiang and Hodson (1959) reported random distribution of European corn borer egg masses in whorl stage field corn, based on analysis of the frequency distribution of data. However, as noted by Ross and Ostlie (1990), much of the early research on European corn borer was conducted on corn grown in hill-planted production systems and may not apply to current row-based production systems with higher plant populations and different plant spatial distributions.

A limitation of previous work on European corn borer distribution on corn is that it has primarily been based on examination of the frequency distribution of insect counts, analyzed using dispersion indices based on the mean-variance relationship (Davis 1994) or by goodness-of-fit to mathematical distributions (Young and Young 1998). These analyses are used to infer the spatial distribution of the insect. However, an aggregated frequency distribution does not always translate into an aggregated spatial distribution in the field, and 
a random frequency distribution does not always translate into a random spatial distribution in the field (Young and Young 1998).

An alternative way to analyze insect spatial distributions is the use of geostatistics (Isaaks and Srivastava 1989). Geostatistical procedures explicitly describe the spatial relationships between insects. In the last ten years, numerous studies have been conducted using geostatistics to describe insect spatial distributions in crops (e.g., Schotzko and O'Keeffe [1989], Midgarden et al. [1993], Ellsbury et al. [1998]).

Overviews of geostatistical analysis with application to insect management are given in Liebhold et al. (1993) and Schotzko and O'Keeffe (1989). A commonly used geostatistical technique is the calculation of a semivariogram to model spatial relationships. A semivariogram plots the sample semivariance (estimated as $1 / 2$ of the average squared difference between data values at the same separation distance) (y-axis) against the specified distance between sample pairs (x-axis) for all separation distances. For aggregated organisms, semivariance is expected to increase as separation between data pairs increases, out to a point where spatial dependence is no longer detected. Several characteristics of semivariograms include the sill (value of the semivariance when it stops increasing, which is equal to the estimated variability in the response), the range (distance at which spatial independence is reached), the lag (distance between sample pairs), and the nugget (semivariance value when $x=0)$.

The objectives of these studies were to characterize the spatial distribution of European corn borer larvae and their resulting feeding damage in whorl stage corn, using geostatistical techniques.

\section{Materials and Methods}

Damage Distribution, 1992-1994. Initial studies focused on characterizing the distribution of larval feeding damage by European corn borer on whorl stage corn. Studies were conducted during 1992-1994 in corn fields at the University of Nebraska's South Central Research \& Extension Center Research Farm, near Clay Center (Clay County), Haskell Ag Laboratory, Concord (Dixon County), and West Central Research \& Extension Center, North Platte (Lincoln County). All fields were planted in rows $76 \mathrm{~cm}$ apart and maintained using standard agronomic practices. No postemergence insecticides were applied. Sampling was conducted in whorl stage corn (stages V610; Ritchie et al. 1993) in late June to mid-July after most $O$. nubilalis egg hatch had occurred and larval damage was visible.

Individual plants were identified as damaged or not damaged based on the presence or absence of damage consistent with European corn borer feeding, i.e., shot-hole feeding damage (Mason et al. 1996). No attempt was made to identify whether live larvae were present at the time of sampling. All plants within a 10 row by 7.6-m block were sampled at North Platte and Clay Center sites. All plants within a 10 row by 100

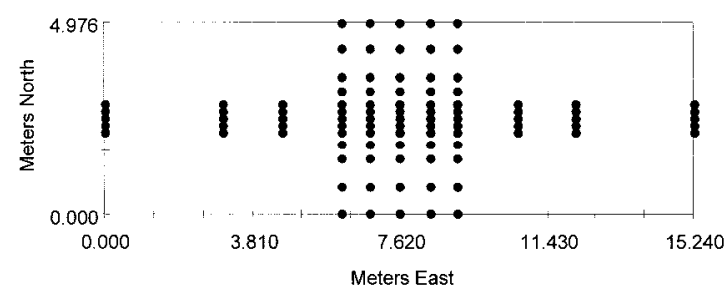

Fig. 1. Sampling pattern for larval and damage distribution studies, Clay Center, NE, 1997.

consecutive plant block were sampled at Concord. Duplicate blocks were sampled in a rectangular grid pattern $(3 \times 3$ or $3 \times 2)$. In 1992 a total of six blocks was sampled at Concord and North Platte, and nine blocks at Clay Center. In 1993, six blocks each were sampled at Concord and North Platte, and in 1994 six blocks were sampled at Concord and nine blocks at North Platte. Minimum distance between blocks was $91 \mathrm{~m}$ at Concord, and $23 \mathrm{~m}$ at North Platte and at Clay Center.

Distribution of Larvae and Damage, 1997. Studies were conducted at Clay Center during 1997 from 17 to 30 June. Corn fields were planted at 12,146 seeds per hectare with $76 \mathrm{~cm}$ between row spacing. All fields were maintained using standard agronomic practices, but no postemergence insecticides were applied. Fields were irrigated as needed, either by overhead sprinkler or furrow irrigation. The sampling pattern used is shown in Fig. 1. For each plant sampled, the presence or absence of $O$. nubilalis feeding damage was recorded. Next, the plant was dissected, and the number of live larvae present recorded. Live larvae were stored in $70 \%$ ethanol and later classified to instar (Higgins et al. 1986). The distance between plants was measured individually for each sample. Because collecting larvae involved destructive sampling, a different field location was chosen for each sample date. The characteristics of the European corn borer population (mean larval density, instar distribution, percentage infested plants) for each sample are shown in Table 1.

Geostatistical Analyses. Data on damage were analyzed using the original data. Larval incidence data were first analyzed by quadratic regression (SAS Institute 1988) to model large scale spatial trends (Young and Young 1998). Where the large scale trend was significant $(P \leq 0.05)$, the residuals from the regression were used to construct the semivariograms.

To calculate semivariograms based on damage from 1992 to 1994, the plant to plant spacing was estimated. At Concord, a uniform between plant interval of $0.26 \mathrm{~m}$ was assumed based on a population of 8,219 plants per hectare. At North Platte and Clay Center, the average between plant interval was calculated separately for each row, based on the number of plants in $7.62 \mathrm{~m}$.

Semivariograms were produced using GS+ software (Robertson 1998). Anisotropic semivariograms were calculated for all data sets at $0,45,90$, and 130 degrees, with a 22.5-degree band width. Omnidirec- 
Table 1. Characteristics of larval European corn borer populations sampled during 1997, Clay Center NE

\begin{tabular}{|c|c|c|c|c|c|c|c|c|}
\hline \multirow{2}{*}{$\begin{array}{l}\text { Sample date and } \\
\text { location }\end{array}$} & \multirow{2}{*}{$\begin{array}{l}\text { Mean larvae } \\
\text { per plant }\end{array}$} & \multicolumn{5}{|c|}{ Instar distribution } & \multirow{2}{*}{$\begin{array}{l}\% \text { of plants } \\
\text { with damage }\end{array}$} & \multirow{2}{*}{$\begin{array}{c}\% \text { of plants } \\
\text { with live larvae }\end{array}$} \\
\hline & & 1 & 2 & 3 & 4 & 5 & & \\
\hline 17 June; B-N pivot & 0.08 & - & - & - & - & - & 7.37 & 5.26 \\
\hline 17 June; W Linear & 0.27 & - & - & - & - & - & 3.16 & 9.47 \\
\hline 18 June; B-N pivot & - & 26 & 15 & 0 & 0 & 0 & - & - \\
\hline 18 June; N Road & 0.46 & 2 & 13 & 3 & 0 & 0 & 30.53 & 25.25 \\
\hline 19 June; N Road & 0.16 & 16 & 18 & 1 & 0 & 0 & 13.69 & 12.63 \\
\hline 23 June; B-N pivot & 0.44 & 8 & 8 & 13 & 0 & 0 & 33.68 & 26.32 \\
\hline 27 June; B-N pivot & 0.63 & 18 & 12 & 7 & 5 & 0 & 29.47 & 29.47 \\
\hline 30 June; B-N pivot & 1.51 & 21 & 43 & 13 & 3 & 4 & 68.42 & 58.95 \\
\hline
\end{tabular}

tional semivariograms are presented here because there was no obvious anisotropy visible in any data set. All semivariograms were calculated to a maximum lag distance of $3.05 \mathrm{~m}$, which is less than half the maximum distance between sample pairs. A variety of equations are commonly used to model variogram data, including spherical and exponential models (Isaaks and Srivastava 1989).

Table 2. Geostatistical description of European corn borer feeding damage on whorl stage corn, $1992-1994$

\begin{tabular}{|c|c|c|c|c|c|c|}
\hline Data set & $\begin{array}{l}\% \text { of plants with } \\
\text { feeding damage }\end{array}$ & Model & Nugget & Sill & Range & $R^{2}$ \\
\hline 1993; NE; Field 4 & 2.9 & None & - & - & - & - \\
\hline 1993; NE; Field 5 & 2.9 & None & - & - & - & - \\
\hline 1993; NE; Field 6 & 3.0 & Spherical & 0.01 & 0.03 & 0.38 & 0.659 \\
\hline 1993; NE; Field 3 & 3.9 & Spherical & 0.01 & 0.04 & 0.32 & 0.300 \\
\hline 1992; SC; Middle West & 4.1 & Spherical & 0.01 & 0.04 & 0.38 & 0.684 \\
\hline 1993; NE; Field 1 & 5.3 & Spherical & 0.01 & 0.05 & 0.45 & 0.783 \\
\hline 1992; SC; Middle North & 5.9 & Spherical & 0.01 & 0.05 & 0.57 & 0.769 \\
\hline A; 1993; NE; Field 2 & 6.4 & Spherical & 0.02 & 0.06 & 0.47 & 0.786 \\
\hline 1992; SC; North East & 7.6 & Spherical & 0.02 & 0.07 & 0.29 & 0.255 \\
\hline 1992; SC; Middle Middle & 10.1 & Spherical & 0.04 & 0.09 & 0.85 & 0.844 \\
\hline 1994; WC; Middle East & 10.3 & Spherical & 0.04 & 0.09 & 0.48 & 0.789 \\
\hline 1992; SC; Middle East & 10.8 & Spherical & 0.02 & 0.10 & 0.46 & 0.719 \\
\hline 1994; WC; North West & 12.0 & Spherical & 0.03 & 0.11 & 0.46 & 0.809 \\
\hline B; 1992; SC; South East & 12.4 & Spherical & 0.02 & 0.11 & 1.01 & 0.869 \\
\hline 1993; WC; South West & 12.8 & Spherical & 0.02 & 0.12 & 0.58 & 0.743 \\
\hline 1994; WC; Middle West & 13.6 & Spherical & 0.06 & 0.12 & 0.72 & 0.863 \\
\hline 1992; SC; South Middle & 14.2 & Spherical & 0.03 & 0.12 & 0.42 & 0.867 \\
\hline 1992; NE; Field 4 & 14.3 & Spherical & 0.03 & 0.12 & 0.50 & 0.945 \\
\hline 1994; WC; Middle North & 14.5 & Spherical & 0.03 & 0.12 & 0.30 & 0.441 \\
\hline 1992; SC; South West & 14.9 & Spherical & 0.02 & 0.13 & 0.80 & 0.906 \\
\hline 1993; WC; Middle West & 14.9 & Spherical & 0.03 & 0.12 & 0.26 & 0.309 \\
\hline 1994; WC; South Middle & 15.3 & Spherical & 0.03 & 0.13 & 0.40 & 0.897 \\
\hline 1994; WC; North East & 15.6 & Spherical & 0.07 & 0.14 & 1.09 & 0.938 \\
\hline 1992; WC; S2, Middle West & 16.0 & Spherical & 0.00 & 0.14 & 0.40 & 0.853 \\
\hline 1994; WC; South East & 16.3 & Spherical & 0.06 & 0.13 & 0.65 & 0.966 \\
\hline 1994; WC; Middle Middle & 17.4 & Spherical & 0.08 & 0.15 & 0.91 & 0.911 \\
\hline C; 1992; WC; S1, North East & 18.5 & Spherical & 0.06 & 0.16 & 1.08 & 0.934 \\
\hline 1993; WC; North West & 19.0 & Spherical & 0.03 & 0.15 & 0.40 & 0.438 \\
\hline 1993; WC; Middle East & 19.0 & Spherical & 0.04 & 0.16 & 0.36 & 0.731 \\
\hline 1992; WC; S1, South East & 19.1 & Spherical & 0.03 & 0.15 & 0.28 & 0.460 \\
\hline 1993; WC; South East & 19.5 & Spherical & 0.03 & 0.16 & 0.45 & 0.917 \\
\hline 1993; WC; North East & 19.7 & Spherical & 0.04 & 0.16 & 0.52 & 0.800 \\
\hline 1992; NE; Field 1 & 20.2 & Spherical & 0.06 & 0.16 & 0.91 & 0.968 \\
\hline 1992; NE; Field 3 & 20.4 & Spherical & 0.04 & 0.16 & 0.60 & 0.919 \\
\hline 1992; NE; Field 2 & 21.2 & Spherical & 0.04 & 0.17 & 0.52 & 0.876 \\
\hline 1992; NE; Field 5 & 22.3 & Spherical & 0.04 & 0.17 & 0.59 & 0.971 \\
\hline 1992; WC; S1, Middle East & 22.4 & Spherical & 0.04 & 0.17 & 0.48 & 0.880 \\
\hline 1992; WC; S1, North West & 22.8 & Spherical & 0.04 & 0.16 & 0.44 & 0.846 \\
\hline 1992; NE; Field 6 & 23.4 & Spherical & 0.04 & 0.18 & 0.45 & 0.862 \\
\hline 1992; WC; S1, Middle West & 24.5 & Spherical & 0.05 & 0.19 & 0.41 & 0.837 \\
\hline D; 1994; WC; South West & 25.5 & Spherical & 0.10 & 0.20 & 1.14 & 0.834 \\
\hline 1994; NE; Field 5 & 41.3 & Spherical & 0.06 & 0.24 & 1.04 & 0.993 \\
\hline 1992; WC; S2, North West & 44.7 & Spherical & 0.05 & 0.23 & 0.39 & 0.684 \\
\hline E; 1994; NE; Field 3 & 45.0 & Spherical & 0.10 & 0.25 & 1.18 & 0.979 \\
\hline 1994; NE; Field 1 & 49.2 & Spherical & 0.11 & 0.25 & 0.93 & 0.954 \\
\hline 1994; NE; Field 2 & 55.9 & Spherical & 0.11 & 0.24 & 0.96 & 0.964 \\
\hline 1994; NE; Field 4 & 58.3 & Spherical & 0.10 & 0.24 & 0.97 & 0.990 \\
\hline F; 1994; NE; Field 6 & 60.6 & Spherical & 0.06 & 0.24 & 1.06 & 0.980 \\
\hline
\end{tabular}

WC, North Platte; NE, Concord; SC, Clay Center. Nugget, sill, range are expressed in meters. 

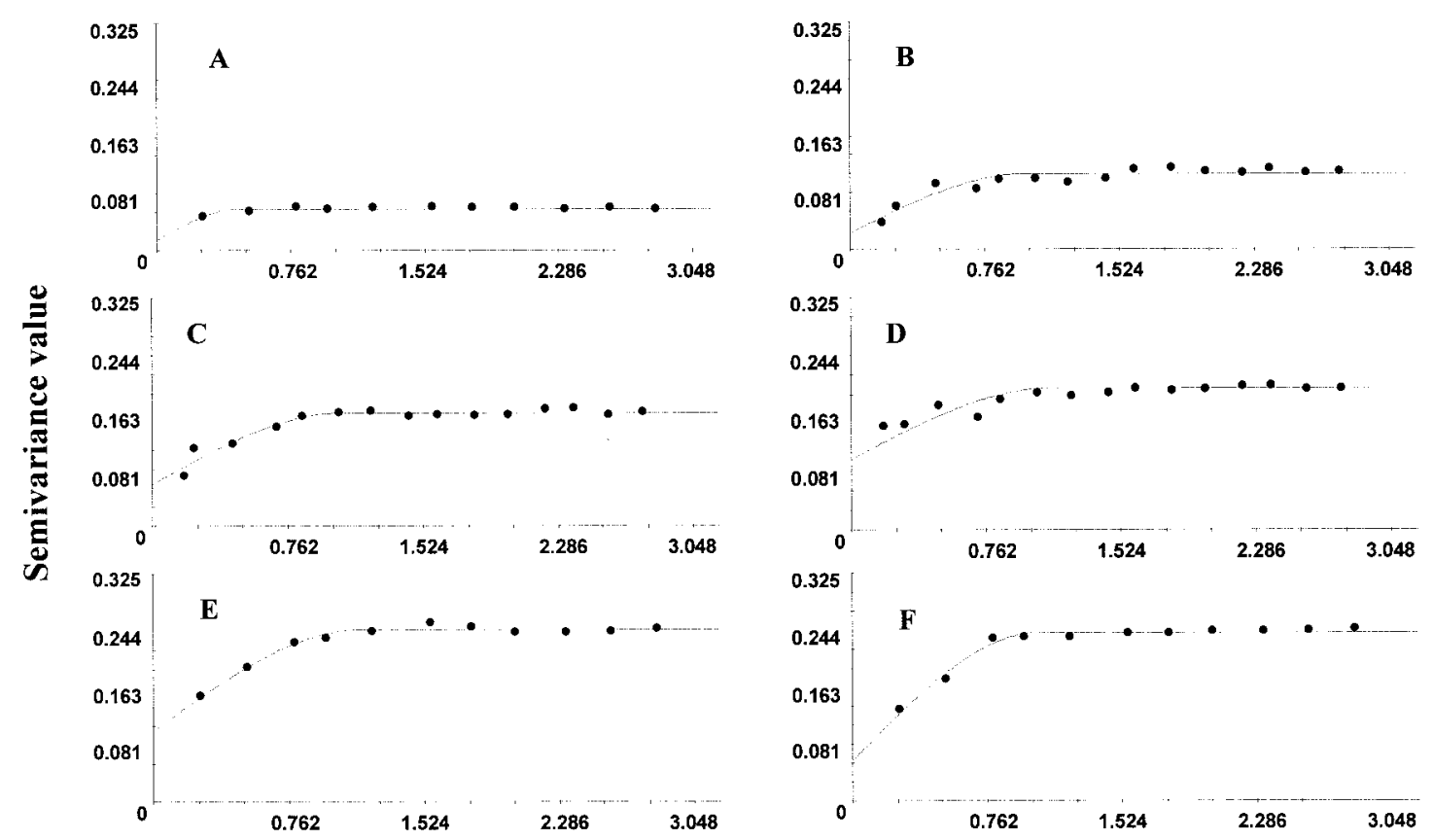

Separation distance $(\mathrm{m})$

Fig. 2. Omnidirectional semivariograms for feeding damage by European corn borer larvae in whorl stage corn, Clay Center, Concord, and North Platte, 1992-1994. Letter designations in figure refer to designations for data sets in Table 2.

A minimum of 30 data pairs per lag are required to adequately estimate the semivariance (Journel and Huijbregts 1978). The number of data pairs per lag were higher for the 1992-1994 data sets (31-4,571 data pairs per lag for North Platte and Clay Center; $980-$ 10,374 data pairs per lag for Concord), than for the 1997 data sets at Clay Center (35-290 data pairs per lag). For each data set, the shortest lag interval was chosen that provided a minimum of 30 data pairs per lag. For 1992-1994 damage data from Concord a uniform lag interval of $0.27 \mathrm{~m}$ was used. For the 1992-1994 North Platte and Clay Center damage data a uniform lag interval of $0.19 \mathrm{~m}$ was used. A uniform lag interval of $0.18 \mathrm{~m}$ was used for the analysis of 1997 damage and larval data, except that the first two lag intervals were combined because there were $<30$ data pairs per lag distance.

\section{Results and Discussion}

Damage Distribution, 1992-1994. The spherical model provided the best fit (based on $R^{2}$ values) for the semivariogram data in 46 out of 48 data sets (Table 2 ). In the two cases where no model was fit there was a very low level of damage (2.9\% damaged plants), and semivariance values were relatively constant across all lag distances, indicating a lack of spatial correlation. Representative semivariograms over a range of damage levels are shown in Fig. 2. The incidence of damage among plants closer together was spatially correlated, and the degree of spatial association decreased as distance between samples increased. The range (distance between data pairs at which spatial independence is reached) varied among the data sets from 0.26 to $2.84 \mathrm{~m}$.

A characteristic of a semivariogram is that the sill is an estimate of the variance of the data. With binomial data, such as that in Fig. 2, the variance is equal to (p) (q), where $p=$ proportion damaged, and $q=1-$ p. By examining the data in Table 2 on proportion of damaged plants, and comparing this with the semivariograms plotted in Fig. 2, it can be seen that the calculated sills are close to the predicted values based on calculation of (p) (q). For example, Fig $2 \mathrm{E}$ is based on a population with $p=0.45$ (Table 2 ), thus $q=0.55$ and (p) $(q)=0.2475$, whereas the calculated sill $=0.25$.

Distribution of Larvae and Damage, 1997. The exponential model provided the best fit (based on $R^{2}$ values) for the larval semivariogram data in three of seven data sets, the spherical model was the best fit for one data set (Table 3), and no model fit three out of seven of the data sets. Semivariograms for all larval data sets are shown in Fig. 3. The range (distance between data pairs at which spatial independence is reached) varied among the larval data sets, from 0.63 to $>3.05 \mathrm{~m}$. The model chosen to describe the semivariogram influences the estimated range. The exponential model assumes a semivariance value that slowly approaches the range, whereas the spherical model rises more quickly to the range. In the exponential model the effective range is assumed to be $3 \mathrm{~A} 0$, where $\mathrm{A} 0$ is the range parameter. In data sets where 
Table 3. Geostatistical description of European corn borer larval distribution on whorl stage corn, Clay Center, NE, 1997

\begin{tabular}{|c|c|c|c|c|c|}
\hline Data set & Model & Nugget & Sill & Range $^{a}$ & $R^{2}$ \\
\hline A; 17 June; B-N plot & None & - & - & - & - \\
\hline B; 17 June; W Linear & Spherical & 0.40 & 2.40 & 2.60 & 0.367 \\
\hline C; 18 June; N Road & Exponential & 0.34 & 0.94 & 2.54 & 0.446 \\
\hline D; 19 June; N Road & Exponential & 0.08 & 0.39 & $>3.05$ & 0.755 \\
\hline E; 23 June; B-N pivot & None & - & - & - & - \\
\hline F; 27 June; B-N pivot & None & - & - & - & - \\
\hline G; 30 June; $\mathrm{B}-\mathrm{N}$ pivot & Exponential & 0.48 & 4.88 & 1.00 & 0.294 \\
\hline
\end{tabular}

Nugget, sill, range are expressed in meters.

${ }^{a}$ For the exponential model the effective range is assumed to be $3 \mathrm{~A}_{0} ; \mathrm{A}_{0}$ is the range parameter. The effective range value for $19 \mathrm{June}$ exceeded the maximum separation distance $(3.05 \mathrm{~m})$ included in the analysis.

the exponential model was chosen based on the $R^{2}$ value, the spherical model also provided a good fit, but with a lower $R^{2}$ value.

The distribution of damage fit the spherical model best in four of seven data sets (Table 4) and no model fit the data in three of seven data sets. Semivariograms for all 1997 damage data are shown in Fig. 4. The range varied from 0.52 to $0.75 \mathrm{~m}$ among the data sets fit to the spherical model. The 1997 damage semivariograms (Fig. 4) are based on fewer data pairs than the 1992 1994 damage semivariograms (Fig. 2). This fact likely explains the greater degree of scatter around the fitted models and the lack of fit to any model in three out of seven of the 1997 data sets.



\section{Separation distance (m)}

Fig. 3. Omnidirectional semivariograms for European corn borer larvae on whorl stage corn, Clay Center, NE, 1997. Letter designations in figure refer to designations for data sets in Table 3. 
Table 4. Geostatistical description of European corn borer feeding damage on whorl stage corn, Clay Center NE, 1997

\begin{tabular}{|c|c|c|c|c|c|c|}
\hline Data set & $\begin{array}{c}\% \text { of plants } \\
\text { with feeding } \\
\text { damage }\end{array}$ & Model & Nugget & Sill & Range & $R^{2}$ \\
\hline A; 17 June, West Linear & 3.2 & None & - & - & - & - \\
\hline B; 17 June, B-N pivot & 7.4 & Spherical & 0.00 & 0.06 & 0.52 & 0.251 \\
\hline C; 18 June, North Road & 30.5 & None & - & - & - & - \\
\hline D; 19 June, North Road & 13.7 & Spherical & 0.01 & 0.14 & 0.75 & 0.382 \\
\hline E; 23 June, B-N pivot & 33.7 & Spherical & 0.04 & 0.24 & 0.68 & 0.536 \\
\hline F; 27 June, B-N pivot & 29.5 & Spherical & 0.02 & 0.22 & 0.54 & 0.326 \\
\hline G; 30 June, B-N pivot & 68.4 & None & - & - & - & - \\
\hline
\end{tabular}

Nugget, sill, range are expressed in meters.

To understand the geostatistical analyses presented, it is useful to review some of the biology of European corn borer (Mason et al. 1996). European corn borer moths lay eggs in masses containing an average of 15 eggs per mass during the first moth flight. Previous research (Chiang and Hodson [1959]) has suggested that these egg masses are laid randomly within a field. At the time of hatch there is an aggregation of neonates associated with an egg mass on a plant. These larvae spread out over the plant, and may migrate to

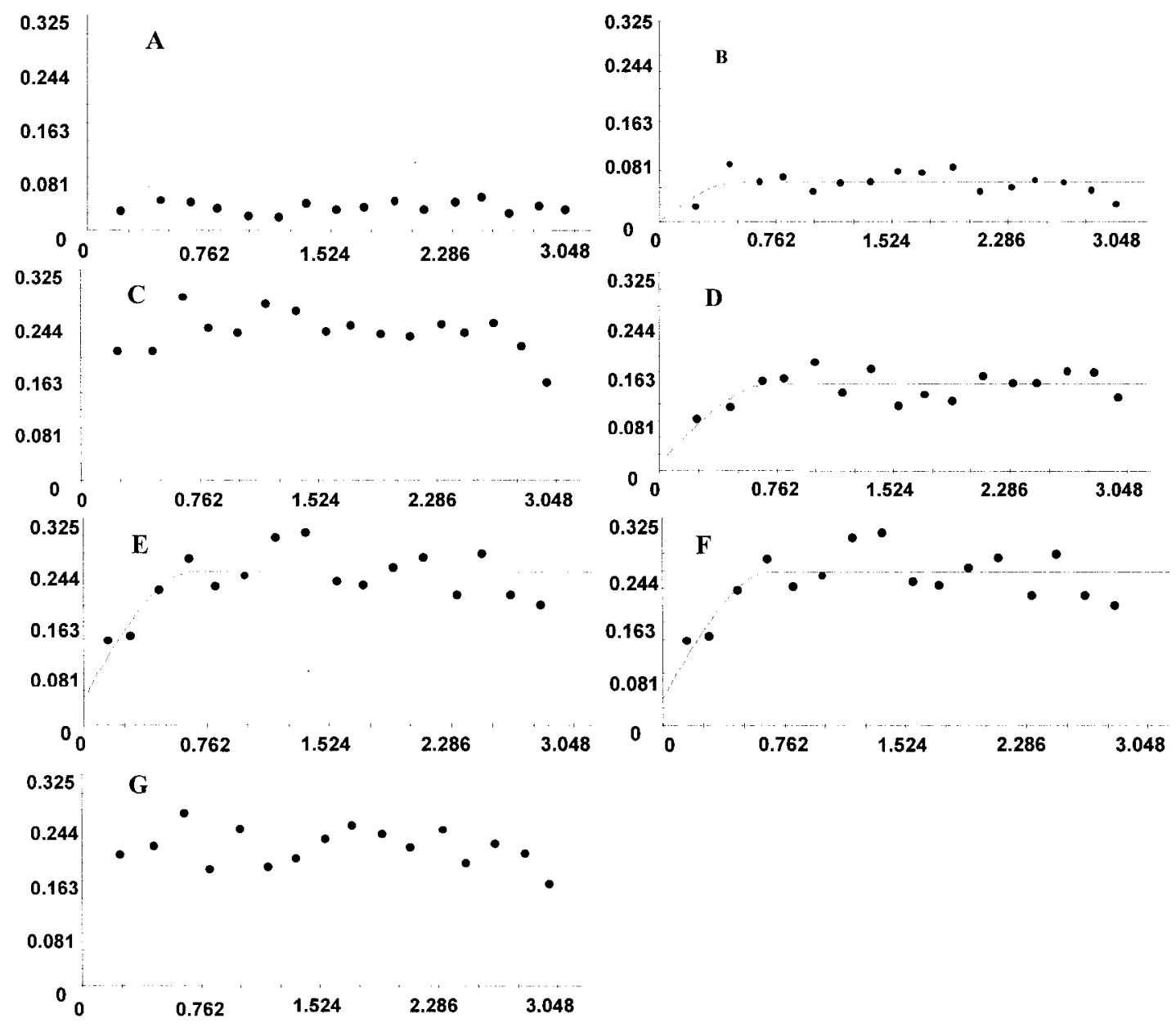

\section{Separation distance $(\mathbf{m})$}

Fig. 4. Omnidirectional semivariograms for feeding damage by European corn borer larvae on whorl stage corn, Clay Center, NE, 1997. Letter designations in figure refer to designations for data sets in Table 4. 
adjacent plants (Ross and Ostlie 1990), decreasing the degree of aggregation at the scale of individual plants. The distribution of damage would be expected to be similar to that of larvae, except that immediately after egg hatch larvae may be present without any visible damage, and due to larval movement and mortality, damage may be present without larvae being present at the time of sampling.

Ross and Ostlie (1990) documented the dispersal of neonate $O$. nubilalis larvae in whorl stage corn. One or more egg masses were placed on a single plant surrounded by uninfested plants, then plants were dissected at various intervals after hatch to document larval locations. Several of their findings are relevant to this study. First they found that there was no significant difference in the number of larvae found by direction, either up or down the row, or on either side of the infested plant in adjacent rows. In the current study, we also found no evidence of directional effects on the spatial distribution of larvae or damage based on visual inspection of anisotropic semivariograms, and thus present omnidirectional semivariograms. Also, Ross and Ostlie (1990) found more than half of the larvae on the plant upon which they hatched. In the $2 \mathrm{yr}$ of their study, $90 \%$ of the larvae found were within $43-47 \mathrm{~cm}$ of the egg mass from which they hatched. This distance included two plants on either side of the infested plant within a row. This is consistent with the relatively small values of the range in this study (from 1.00 to $>3.05 \mathrm{~m}$, with the all but one of variograms for larvae showing a range $<2.6 \mathrm{~m}$ ).

Implications for Pest Management. Management decisions concerning $O$. nubilalis in whorl-stage corn must be made while larvae are feeding within the whorl, and are still accessible to chemical controls. A commonly recommended scouting procedure is to determine the frequency of damaged plants, and to estimate larval density by destructively sampling a subsample of damaged plants (Calvin and Van Duyn 1999). A common recommendation is to sample 20-25 consecutive plants at a location in the field and repeat this at multiple locations within a field (e.g., Tollefson and Calvin 1994). This study has documented that plant damage and O. nubilalis larvae may be spatially correlated in plants from 0.2 to $>3.05 \mathrm{~m}$ apart. Thus, consecutive plant samples may not represent statistically independent sample units, thus violating one of the assumptions of random sampling (Binns and $\mathrm{Ny}$ rop 1992). Additional studies are needed to develop statistically reliable sampling plans for European corn borer larvae in whorl stage corn.

Site-specific management is being researched in many crops (e.g., Pierce and Sadler 1997) including corn. One assumption involved in site-specific pest management is that pest densities can be mapped (either by sampling or remote-sensing), and the field managed based on the map, rather than field averages. Organisms which exhibit small-scale spatial dependence only over short distances may require a large number of samples to adequately map their distribution, if sampling is conducted directly. If sampling is conducted by remote-sensing the spatial resolution of the sensing procedure must be consistent with the distance over which samples are spatially dependent.

\section{Acknowledgments}

We thank Bob Peterson (Dow AgroSciences) and Tom Hunt (University of Nebraska-Lincoln) for review of the manuscript, and our summer employees for help in collecting the data. This research was supported in part by University of Nebraska Agricultural Experiment Station Project 48-022. This paper is Journal Series No. 13259 of the Nebraska Agricultural Experiment Station and Paper No. 1089 of the Department of Entomology, University of Nebraska-Lincoln.

\section{References Cited}

Binns, M. R., and J. P. Nyrop. 1992. Sampling insect populations for the purpose of IPM decision making. Annu. Rev. Entomol. 37: 427-453.

Calvin, D. D., M. C. Knapp, K. Xingquan, F. L. Poston, and S. M. Welch. 1986. Using a decision model to optimize European corn borer (Lepidoptera: Pyralidae) egg-mass sampling. Environ. Entomol. 15: 1212-1219.

Calvin, D. D., and J. W. Van Duyn. 1999. European corn borer, pp. 78-82. In K. L. Steffey, M. E. Rice, J. All, D. A. Andow, M. E. Gray, and J. W. Van Duyn (eds.), Handbook of corn insects. Entomological Society of America, Lanham, MD.

Chiang, H. C., and A. C. Hodson. 1959. Distribution of the first-generation egg masses of the European corn borer (Pyrausta nubilalis) in fields. J. Econ. Entomol. 52: 409411.

Davis, P. M. 1994. Statistics for describing populations, pp. 34-54. In L. P. Pedigo and G. D. Buntin (eds.), Handbook of sampling methods for arthropods in agriculture. CRC, Boca Raton, FL.

Ellsbury, M. M., W. D. Woodson, S. A. Clay, D. Malo, J. Schumacher, D. E. Clay, and C. G. Carlson. 1998. Geostatistical characterization of the spatial distribution of adult corn rootworm emergence. Environ. Entomol. 27: $910-917$.

Higgins, R. A., G. Brandsberg, K. Fischer, and R. Wolf. 1986. European corn borer phenology and management models, User Documentation. Kansas Cooperative Extension Service, Manhattan, KS.

Isaaks, E. H., and R. M. Srivastava. 1989. An introduction to applied geostatistics. Oxford University Press, New York

Journel, A. G., and C. J. Huijbregts. 1978. Mining geostatistics. Academic, New York

Liebhold, A. M., R. E. Rossi, and W. P. Kemp. 1993. Geostatistics and geographic information systems in applied insect ecology. Annu. Rev. Entomol. 38: 303-327.

Mason, C. E., M. E. Rice, D. D. Calvin, J. W. Van Duyn, W. B. Showers, W. D. Hutchison, J. F. Witkowski, R. A. Higgins, D. W. Onstad, and G. P. Dively. 1996. European corn borer ecology and management. North Central Regional Extension Publication 327. Iowa State University, Ames, IA.

Midgarden, D. G., R. R. Youngman, and S. J. Fleischer. 1993. Spatial analysis of counts of western corn rootworm adults on yellow sticky traps in corn: geostatistics and dispersion indices. Environ. Entomol. 22: 1124-1133.

Pierce, F. J., and E. J. Sadler (eds.). 1997. The state of site specific management in agriculture. Proceedings of a Symposium, St. Louis, MO, 31 October 1995. American Society of Agronomy, Crop Science Society of America, and Soil Science Society of America, Madison, WI. 
Ritchie, S. W., J. J. Hanway, and G. O. Benson. 1993. How a corn plant develops. Report 48. Cooperative Extension Service, Iowa State University, Ames, IA.

Robertson, G. P. 1998. GS + user's guide: geostatistics for the environmental sciences, version 3:1 for Windows. Gamma Design Software, Plainwell MI.

Ross, S. E., and K. R. Ostlie. 1990. Dispersal and survival of early instars of European corn borer in field corn. J. Econ. Entomol. 83: 831-836.

SAS Institute. 1988. SAS/STAT user's guide, release 6.03 ed. SAS Institute, Cary, NC.

Shelton, A. M., J. P. Nyrop, A. Seaman, and R. E. Foster. 1986. Distribution of European corn borer egg masses and larvae on sweet corn in New York. Environ. Entomol. 15: 501-506.

Schotzko, D. J., and L. E. O’Keeffe. 1989. Geostatistical description of the spatial distribution of Lygus hesperus
(Heteroptera: Miridae) in lentils. J. Econ. Entomol. 82: $1277-1288$

Sorensen, C. E., J. W. Van Duyn, G. G. Kennedy, J. R. Bradley, Jr., C. S. Eckel, and G.C.J. Fernandez. 1995. Evaluation of a sequential egg mass sampling system for predicting second-generation damage by European corn borer in field corn in North Carolina. J. Econ. Entomol. 88: 1316-1323.

Tollefson, J. J., and D. D. Calvin. 1994. Sampling arthropod pests in field corn, pp. 433-473. In L. P. Pedigo and G. D. Buntin (eds.), Handbook of sampling methods for arthropods in agriculture. CRC, Boca Raton, FL.

Young, L. J., and J. H. Young. 1998. Statistical ecology: A population perspective. Kluwver Academic, Boston, MA.

Received for publication 8 March 2001; accepted 11 October 2001. 